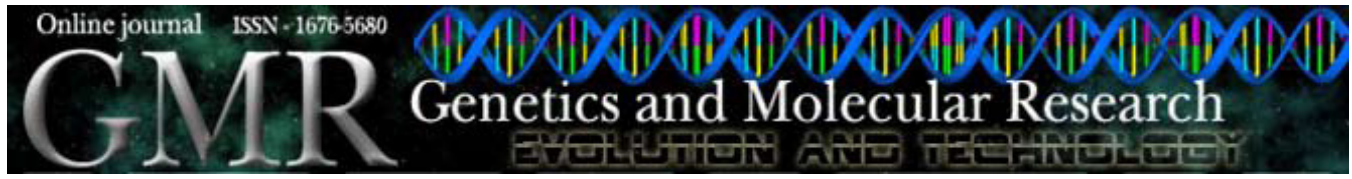

\title{
Frequency of FMR1 premutation in individuals with ataxia and/or tremor and/or parkinsonism
}

\author{
A.H.O. Reis ${ }^{1}$, A.C.S. Ferreira ${ }^{2}$, K.B. Gomes ${ }^{2}$, M.J.B. Aguiar ${ }^{3,4}$, \\ C.G. Fonseca ${ }^{1}$, F.E. Cardoso ${ }^{5,6}$, V.C. Pardini ${ }^{2}$ and M.R.S. Carvalho ${ }^{1,4}$ \\ ${ }^{1}$ Departamento de Biologia Geral, Instituto de Ciências Biológicas, \\ Universidade Federal de Minas Gerais, Belo Horizonte, MG, Brasil \\ ${ }^{2}$ Departamento de Genética Humana, Instituto Hermes Pardini, \\ Belo Horizonte, MG, Brasil \\ ${ }^{3}$ Departamento de Pediatria, Faculdade de Medicina, \\ Universidade Federal de Minas Gerais, Belo Horizonte, MG, Brasil \\ ${ }^{4}$ NUPAD, Núcleo de Pesquisa em Apoio ao Diagnóstico, Faculdade de Medicina, \\ Universidade Federal de Minas Gerais, Belo Horizonte, MG, Brasil \\ ${ }^{5}$ Departamento de Clínica Médica, Faculdade de Medicina, \\ Universidade Federal de Minas Gerais, Belo Horizonte, MG, Brasil \\ ${ }^{6}$ Serviço de Neurologia, Ambulatório Bias Fortes, \\ Hospital das Clínicas de Minas Gerais, Belo Horizonte, MG, Brasil \\ Corresponding author: M.R.S. Carvalho \\ E-mail:mraquel@icb.ufmg.br
}

Genet. Mol. Res. 7 (1): 74-84 (2008)

Received April 20, 2007

Accepted December 15, 2007

Published January 29, 2008

\begin{abstract}
A late onset neurological syndrome in carriers of premutation in FMR1 gene was recently described. The condition was named fragile-X-associated tremor/ataxia syndrome (FXTAS) and includes intentional tremor, cerebellar ataxia, parkinsonism, and cognitive deficit. We ascertained the contribution of FMR1 premutation to the phenotypes ataxia, tremor and/or parkinsonism. Sixty-six men over 45 years old presenting these symptoms, isolated or combined, were tested. Also, 74 normal men, randomly chosen in the population, formed the control group. In the patient group, no premutation carrier was found, which is in agreement with other observed frequencies reported elsewhere (0-5\% variation).
\end{abstract}


No significant differences were found when comparing gray zone allele frequencies among target and control groups. The FXTAS contribution in patients with phenotypic manifestations of FXTAS was $15 / 748(2 \%)$. The presence of gray zone alleles is not correlated with FXTAS occurrence.

Key words: FMR1; FXTAS; Ataxia; Parkinsonism; Premutation; Tremor

\section{INTRODUCTION}

Fragile X mental retardation 1 (FMR1) or fragile X syndrome (OMIM \# 300604) is a dominant $\mathrm{X}$-linked genetic disorder, with incomplete penetrance $(30 \%$ in women and $80 \%$ in men). Fragile $X$ syndrome frequency varies from 1:4000 to 1:6000 men in Caucasian populations (Martin et al., 1980; Richards et al., 1981; Flannery et al., 1995; Turner et al., 1996; de Vries et al., 1997, 1999; Capelli et al., 2005; Van Esch, 2006).

The phenotype is produced by the expansion of a CGG repeat in the 5'-untranslated region of FMR1 gene. Normal individuals have alleles with 5-40 copies of the CGG motif and premutation carriers have 59-200 copies. Repeats larger than 200 copies of CGG motif induce gene inactivation leading to the typical clinical picture. Alleles with 41-60 CGG repeats are classified as gray zone alleles, since it does not characterize a normal individual and also does not constitute a premutation. The prognostic importance of gray zone alleles has been disputed. There is also some discussion in the literature concerning where to set the boundaries between normal size and gray zone and between gray zone and premutation size. Usually, FMR1 phenotype is produced by the expansion of CGG repeats, while loss of FMR1 function due to point mutations has seldom been reported (Jin and Warren, 2003; Leehey et al., 2003; Oostra and Willemsen, 2003; Mandel and Biancalana, 2004; Capelli et al., 2005).

Recently, FMR1 premutation was associated with a clinical picture formed by intentional tremor and cerebellar ataxia, parkinsonism and cognitive deficit. This new condition was called fragile-X-associated tremor/ataxia syndrome (FXTAS; OMIM \# 300623). Other symptoms such as memory loss, executive function deficits, dementia (only in affected men) and autonomic dysfunction (impotence, urinary and bowel incontinence) have also been described (Hagerman and Hagerman, 2001; Hagerman et al., 2001; Brunberg et al., 2002; Jacquemont et al., 2003; Rogers et al., 2003; Tan et al., 2004; Baba and Uitti, 2005; Greco et al., 2002, 2006). It has been suggested that some patients with Parkinson disease or multiple system atrophy could also be FXTAS carriers (Tan et al., 2004; Hall et al., 2005; Kamm and Gasser, 2005).

Postmortem brain examination of FXTAS patients has revealed eosinophilic intranuclear inclusions in neurons and astrocytes and brain atrophy with Purkinje cell loss. Such inclusions have not been observed in patients with complete FMR1 mutation (Brunberg et al., 2002; Greco et al., 2002, 2006). Drosophila and mouse animal models for FMR1 premutation exhibit not only nuclear inclusions, but also cytoplasmic ones, suggesting that different pathological mechanisms can be involved in these organisms (Jin et al., 2003; Willemsen et al., 2003). 
FMR1 premutation frequencies have been estimated in Caucasian populations to be 1:259 for women and 1:813 for men (Rousseau et al., 1995; Dombrowski et al., 2002). For men over 50 years, FXTAS frequency has been estimated to 1:3000 (Jacquemont et al., 2004; Hagerman and Hagerman, 2004a).

Most studies have focused on FXTAS frequency among FMR1 carriers, and most patients have been ascertained due to their relationship to patients with fragile X syndrome. The contribution of FMR1 premutation to the phenotype ataxia-tremor-parkinsonism has been only seldom addressed. Discordant results on the contribution of FMR1 premutation to these phenotypes have been published and could be attributed to the relatively broad range of phenotypes included in FXTAS as well as to ascertainment bias (MacPherson et al., 2003; Tan et al., 2004; Van Esch et al., 2004; Zühlke et al., 2004; Brussino et al., 2005; Seixas et al., 2005). Correct diagnosis would contribute to genetic counseling of these families (Tan et al., 2004; Hall et al., 2005; Kamm and Gasser, 2005). Therefore, we estimated the frequency of FMR1 premutation in patients with ataxia and/or tremor and/or parkinsonism ascertained by a neurological clinic that does not take care of fragile $\mathrm{X}$ families.

\section{MATERIAL AND METHODS}

Sixty-six men over 45 years old with ataxia, tremor and/or parkinsonism were tested. Besides, 74 normal men, randomly chosen in the population, formed the control group. The whole study and methods were approved by the Ethics in Research Committee of Universidade Federal de Minas Gerais. All the individuals were sampled in collaboration with Hermes Pardini Institute and Hospital das Clínicas of Universidade Federal de Minas Gerais.

Genomic DNA was extracted from blood samples with Puregene Kit (Gentra, USA) and from buccal swabs with a protocol reported in the literature (Sambrook and Russell, 2001). Polymerase chain reaction (PCR) amplifications of the FMR1 5'-untranslated region were performed with a previously described primer set (Fu et al., 1991). Each $15-\mu \mathrm{L}$ (total volume) reaction contained $50 \mathrm{mM} \mathrm{KCl}, 20 \mathrm{mM}$ Tris-HCl, $\mathrm{pH} 8.4,1.5 \mathrm{mM} \mathrm{MgCl}, 200 \mu \mathrm{M}$ of each dNTP (Buffer II - Accuprime System, Invitrogen, USA), $150 \mu \mathrm{M}$ 7-deaza-dGTP (Amersham Pharmacia Biotech, USA), $10 \%$ dimethylsulfoxide, $10 \mathrm{pM}$ of each fluorescent labeled primer, 1 U Taq DNA polymerase (Accuprime System, Invitrogen, USA), and 100 ng genomic DNA. PCR amplifications entailed an 8-min initial denaturation step at $95^{\circ} \mathrm{C}$, followed by 40 cycles of $30 \mathrm{~s}$ denaturation at $95^{\circ} \mathrm{C}, 50 \mathrm{~s}$ annealing at $66^{\circ} \mathrm{C}$ and $1 \mathrm{~min}$ extension at $72^{\circ} \mathrm{C}$, and finally an 8-min last extension step at $72^{\circ} \mathrm{C}$.

PCR products were separated on $4 \%$ denaturing polyacrylamide electrophoresis gels. Allele visualization was performed in an Fmbioll fluorescent reader (Hitachi Denshi, Japan) or by silver staining (Sambrook and Russell, 2001). Allele size and number of CGG repeats were estimated by comparison with DNA ladders (Power Plex, Promega, USA) carried out with the AlphaDigiDoc 1200\&1201 software (Alpha Innotech, UK). Allele frequencies observed in the patients and the control group were compared by the Fisher exact test.

\section{RESULTS}

Results of PCR amplification of the 5'-untranslated region of FMR1 gene are shown

Genetics and Molecular Research 7 (1): $74-84$ (2008) www.funpecrp.com.br 
in Figure 1. Sharp bands were obtained for all individuals included in the analysis. Better PCR yields were obtained for alleles in the normal range than for premutation ones.

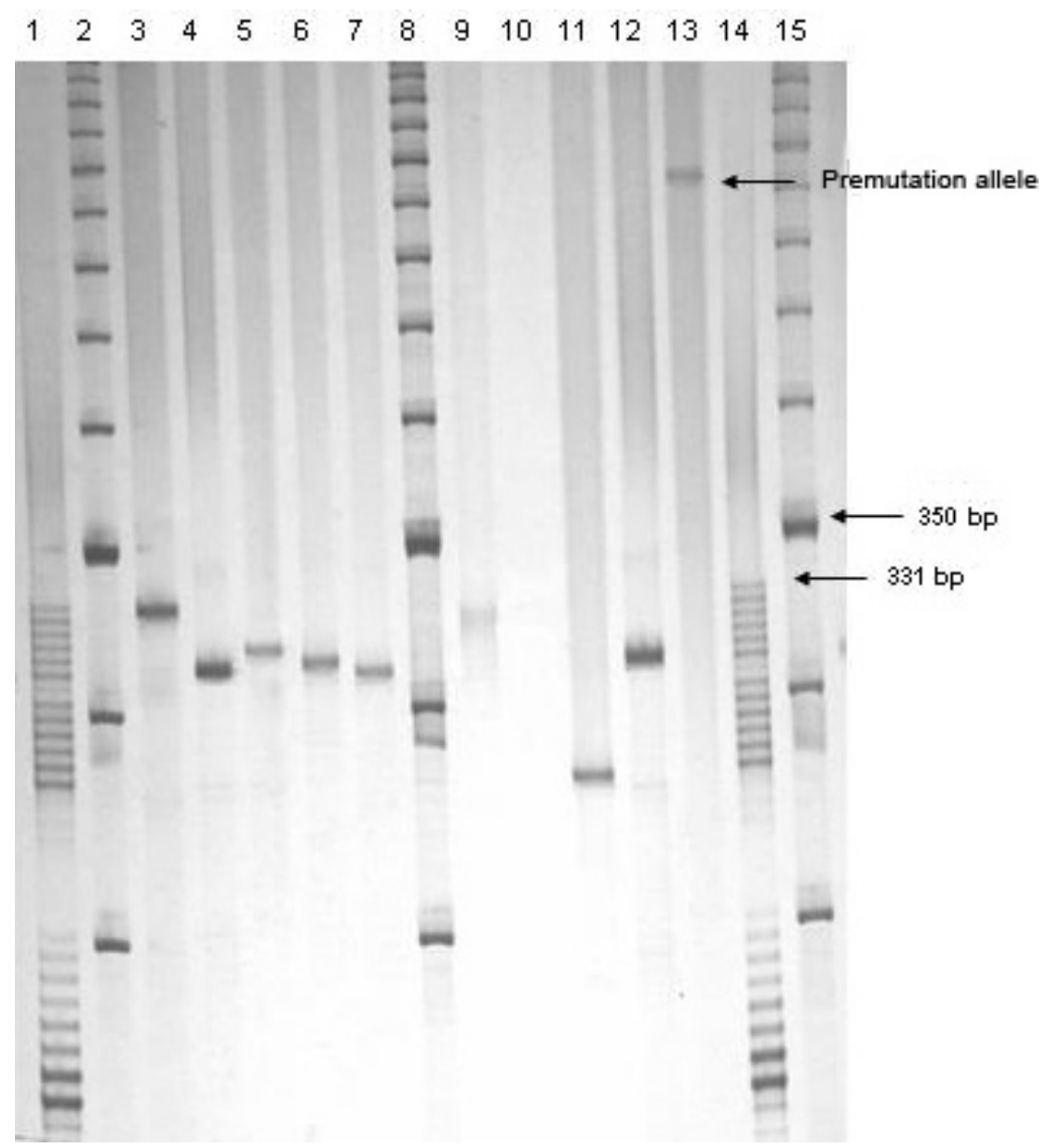

Figure 1. Silver-stained polyacrylamide gel showing the amplification of segment containing the CGG repeats of FMR1 gene. The arrow in Lane 13 points to the premutation size allele. Lanes 3, 4, 5, 6, 7, 9, 11 and 12: normal size alleles. Lane 10: PCR negative control. Lanes 2, 8 and 15: 50-bp DNA Ladder (Amersham Pharmacia Biotech, USA). Lanes 1 and 14: F13A/FES Ladder (Power Plex, Promega, USA).

Distribution of allele frequencies in both patient and control groups is shown in Figure 2. The most frequent alleles were those ranging from 28 to 30 CGG repeats, which is in good agreement with previous descriptions in the literature (Capelli et al., 2005; Willemsen et al., 2005; Van Esch, 2006). Gray zone alleles were detected among patients as well as in the control group with frequencies of 3.03 and $2.70 \%$, respectively $(\mathrm{P}=0.38$, Fisher exact test). Gray zone allele frequencies in these two groups were also similar to those previously reported (Haddad et al., 1999; Garcia Arocena et al., 2004; Toft et al., 2005). No premutation alleles 
were found among ataxia, tremor and/or parkinsonism individuals and one premutation allele was found in the control group $(\mathrm{P}=0.53$, Fisher exact test $)$.

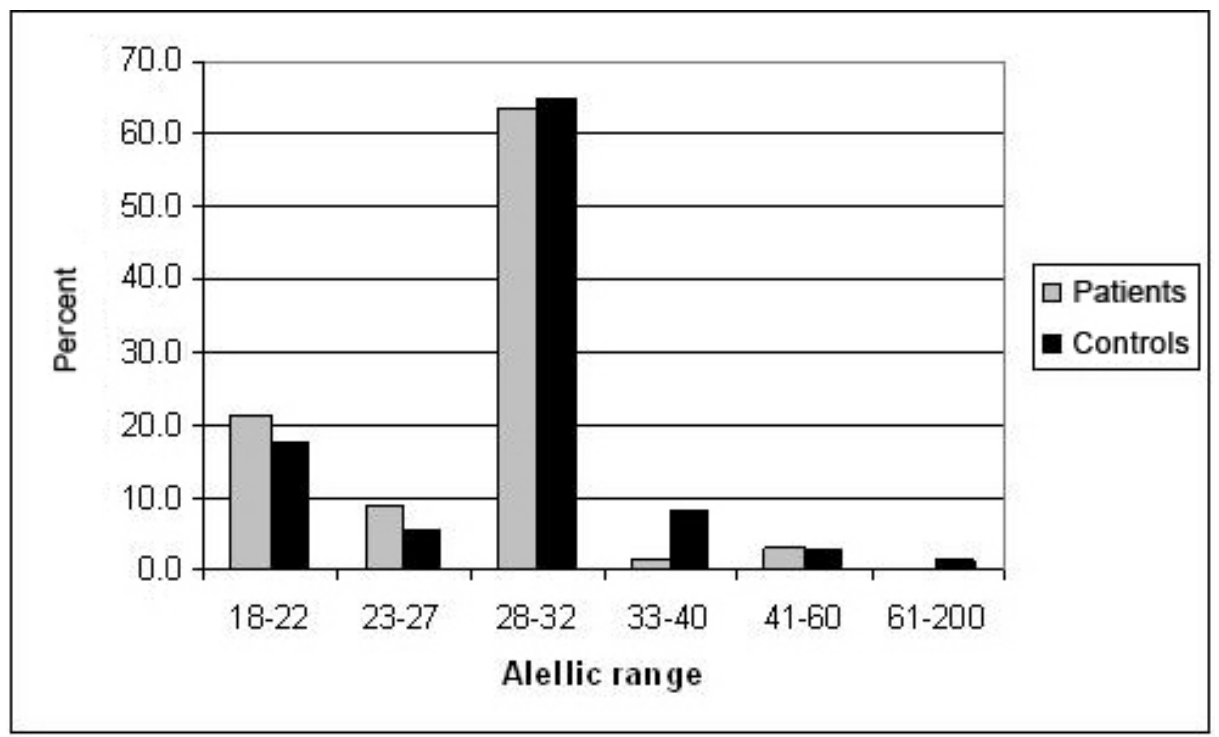

Figure 2. Distribution (in percent) of allele frequencies in patient and control groups. The allele is labeled according to numbers of CGG.

\section{DISCUSSION}

The symptoms resulting from FMR1 premutation were first observed in normal transmitter males screened in genetic counseling clinics due to their relationship with fragile $\mathrm{X}$ syndrome patients.

In a first effort for ascertaining the contribution of FMR1 premutation to ataxiatremor-parkinsonism phenotype, 59 individuals with neurodegenerative disorders were investigated (MacPherson et al., 2003). Three patients (5\%) showed abnormal numbers of CGG repeats (two in gray zone and one with a premutation). Since then, several studies reporting a smaller contribution of FMR1 premutations to neurodegenerative phenotypes were published, where FMR1 premutation frequencies ranged from $0-5 \%$. These data are shown in Table 1 (Garcia Arocena et al., 2004; Van Esch et al., 2004; Tan et al., 2004; Zühlke et al., 2004; Biancalana et al., 2005; Brussino et al., 2005; Seixas et al., 2005; Toft et al., 2005). Some issues in these reports deserve a closer scrutiny.

Most of these samples as well as ours include only males, since PCR detection of premutation in females is not accurate. Sample size and patient inclusion criteria diverged considerably among the studies reported. Sample size ranged from 59 to 243 males over 50 years old. The more stringent the clinical criteria, the smaller the sample was, so that composed phenotypes were ascertained only in those reports with the smaller samples.

Genetics and Molecular Research 7 (1): $74-84$ (2008) www.funpecrp.com.br 
Frequency of FMR1 in ataxia, tremor or parkinsonism

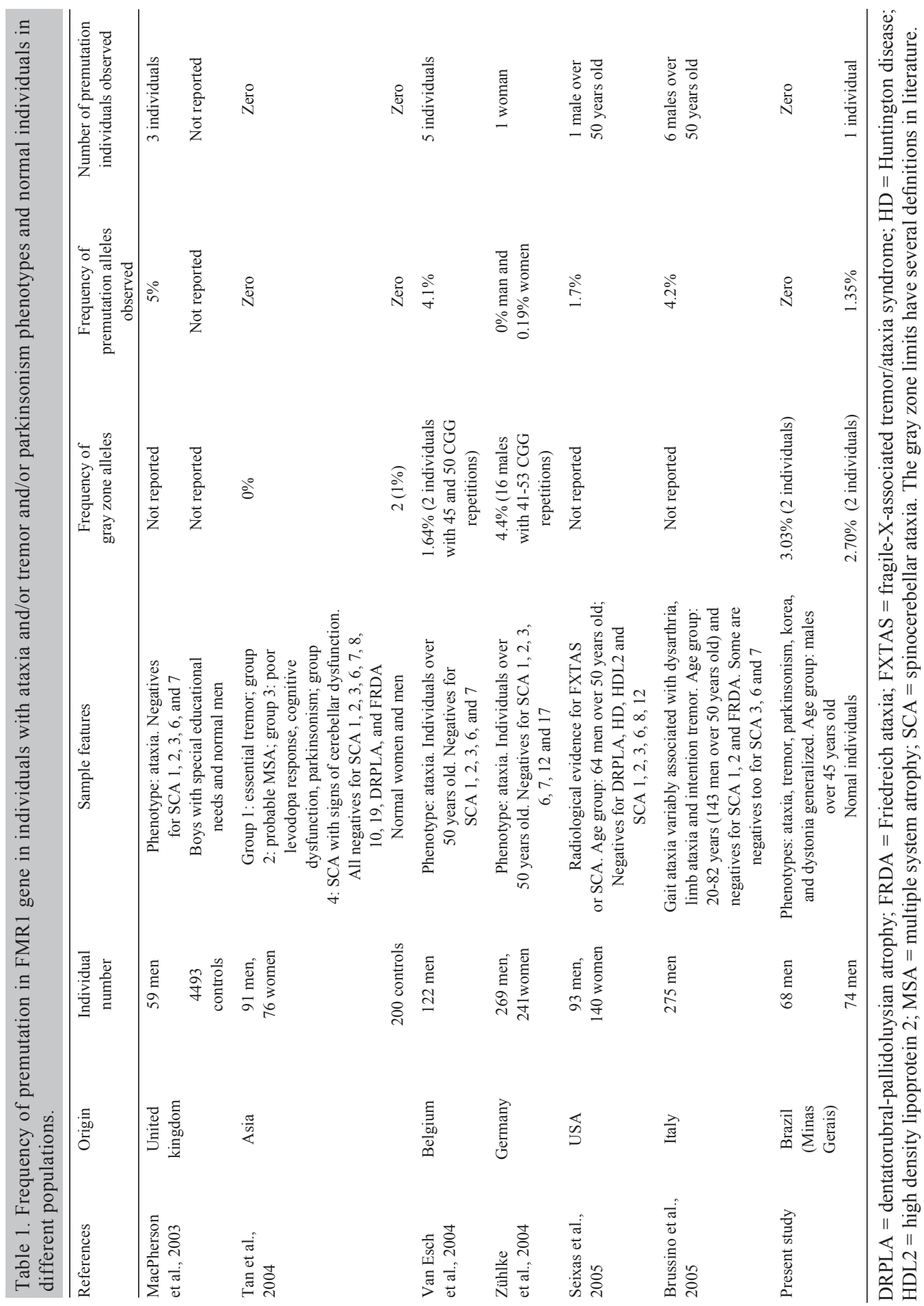

Genetics and Molecular Research 7 (1): $74-84$ (2008) www.funpecrp.com.br 
Samples also differed in the homogeneity of the phenotype investigated; in some samples the phenotype is described as ataxia only, while in some others, clinical criteria were expanded to include chorea and dystonia. Besides, in some samples with only ataxia, clinical heterogeneity can be inferred, because patients had been previously tested for Huntington's disease and/or dentatorubral-pallidoluysian atrophy.

Samples also differed in the number of diseases for which the patients had been previously tested. When more conditions producing ataxia or movement disturbances are excluded, the probability of ascertaining patients with FMR1 premutation increases. Therefore, differences in previous evaluation of patients may also account for part of the differences in the frequencies of FMR1 premutation observed among the studies. Besides, an additional source of ascertainment bias could be supposed in those studies carried out at fragile X syndrome care centers.

In the present study, criteria for inclusion of individuals in the patient sample were homogeneous for gender (only males) and age (above 45 years). Phenotypes tested were ataxia with or without associated symptoms (13.2\% of the patients) and other phenotypes from the FXTAS spectrum without ataxia ( $86.8 \%$ of the patients). Patients had not been routinely screened for other cerebellar ataxia and/or neurodegenerative diseases. No premutation carrier male was identified in the patient sample in our study. These results do not differ from those previously reported by most previous studies (Garcia Arocena et al., 2004; Tan et al., 2004; Toft et al., 2005).

The frequency of FMR1 premutation in the normal males of our study (1/74) was higher than that reported in other studies on FXTAS (see Table 1). It is also higher than the frequency estimated for the Caucasian population (13/10,572; Dombrowski et al., 2002). However, this difference was not statistically significant $(\mathrm{P}=0.09$, Fisher exact test) suggesting a casual finding. In the same way, the difference observed in premutation frequencies between patients $(0 / 66)$ and controls $(1 / 74)$ in the present study was not significant $(\mathrm{P}=0.53$, Fisher exact test).

Frequencies of gray zone alleles among patients from different studies were also similar to those described in controls, whenever this information was available (Table 1). Frequencies of gray zone alleles ranging from 2 to $5 \%$ have been already reported in normal individuals (Haddad et al., 1999; Garcia Arocena et al., 2004; Toft et al., 2005). In the present study, frequencies of gray zone alleles in the patient sample and control group are within this interval.

Aiming at establishing the average contribution of the FMR1 premutation for the phenotype ataxia, tremor and parkinsonism, we critically reviewed the literature (Table 1). In total, 748 males aged 50 years or more were tested, among whom the average frequency of premutation carriers was 15/748 (approximately 2.0\%). Among 457 females tested, only one FMR1 premutation carrier was identified giving an average contribution of $0.22 \%$. Besides the (lower) frequency, the phenotypic manifestations in women were also milder (Hagerman et al., 2004; Jacquemont et al., 2004; Berry-Kravis et al., 2005).

In addition to the higher frequency of clinical manifestations in males carrying premutation alleles, the phenotype is usually more severe in men. Two hypotheses have been proposed to explain the gender differences in frequency and severity of symptoms in FMR1 premutation carriers: a) presence of one normal FMR1 allele, expressed in those cells that randomly inactivate the premutation allele; b) sex-specific effects, because women under estrogen-based hormonal replacement therapy present milder symptoms of FXTAS (Hagerman et al., 2004; Berry-Kravis et al., 2005).

The FXTAS phenotype described originally was discovered in premutation male carriers in families where the fragile X mental retardation 1 segregates. These patients showed 
specific and diverse clinical manifestations, some with ataxia, tremor and parkinsonism, others with combinations of these symptoms, and still some patients with only one of them (Hagerman and Hagerman, 2001; Hagerman et al., 2001; Greco et al., 2002; Jacquemont et al., 2003). Gradually, the spectrum of clinical manifestations was expanded to include autonomic disturbances, seizures, loss of cognitive abilities, anxiety, dementia, low IQ results, emotional instability, obsessive-compulsive disturbances, deafness, schizotypic personality and/or depression, accented irritability, and episodes of loss of self-control (Baba and Uitti, 2005; Greco et al., 2006; Grigsby et al., 2006, 2007).

Some patients showed diffuse cerebral or cerebellar atrophy, peripheral neuropathy, and sensitivity disturbances (Hagerman and Hagerman, 2004b; Jacquemont et al., 2004; Van Dam et al., 2005; Grigsby et al., 2007). It is noteworthy that some of the symptoms described in FXTAS are not seldom seen by the fifth decade of life and thereafter, when the symptoms of this condition begin. Consequently, data must be carefully analyzed in order to avoid fortuitous associations.

Another interesting question is the contribution of the FXTAS to movement disorders in general. Individuals with Parkinson disease (414 individuals), essential tremor (152 individuals), and multiple system atrophy (15 individuals) had already been tested. No contribution of FMR1 premutation for those phenotypes was detected (Garcia Arocena et al., 2004; Tan et al., 2004; Toft et al., 2005).

A strong variation has been observed in FXTAS age of onset and clinical course. A variation in penetrance as a function of age was estimated to be 17 to $75 \%$ between the ages of 50 and 80 years or more (Jacquemont et al., 2004). The disorder progresses slowly leading to death in 10 to 15 years. These interindividual variations may be produced by interactions between FMR1 premutation and alleles in other loci, working on a digenic or multifactorial basis. Recently, an example of digenic inheritance for ataxia phenotype was identified in a 58-year-old woman in whom alterations in two different genes were found, one FMR1 premutation and one mutation in the Friedreich ataxia gene. Interestingly, both alterations are due to expansions in trinucleotide repeats (Zumrova et al., 2005). Another aspect that may suggest a complex basis for individual variation in FXTAS clinical course is that during the disease progression symptoms overlap with common conditions, such as Parkinson's or Alzheimer's diseases. Therefore, the condition is possibly heterogeneous with the FMR1 premutation working as a main component. These aspects as well as the contribution of environmental factors have not yet been investigated.

\section{FINAL COMMENTS}

The main difficulty for the characterization of FXTAS is investigating patients with the full syndrome, since the overlapping of ataxia, tremor and parkinsonism is rare. Due to this, the majority of the investigated cases were identified in services that care for families with FMR1, where the frequency of premutation carriers is high. On the other hand, the minimum criterium for diagnosis of the disorder has not been established. Therefore, the question that is placed is: which is the contribution of the FXTAS for the neurodegenerative disorders with which it presents partial phenotype overlapping?

In the literature, the frequency of premutation carriers between individuals with suggestive symptoms varies from $0-5 \%$. The variation found in this frequency can be due to the relatively small size of samples in the majority of published studies. Among the published

Genetics and Molecular Research 7 (1): 74-84 (2008) www.funpecrp.com.br 
studies, there are differences in the criteria for inclusion of the patients in the sample, in terms of phenotypes and number of disorders whose diagnoses had been previously excluded on the basis of molecular screens. Moreover, the samples show different genetic backgrounds which can explain in part the observed variation.

In a recent meta-analysis study (Jacquemont et al., 2006), the frequency of premutation carriers was compared with the size of expansion found in patients with diverse phenotypes. The premutations in the FMR1 gene were shown in $2 \%$ of male patients with ataxia and beginning of symptoms after the age of 50. This frequency was thirteen times higher than that observed in the general population. On the other hand, the highest allele frequencies were observed in patients not belonging to families with FMR1, suggesting that it can have a bias favoring the ascertainment of mild pictures when the individual is related to an FMR1 case. These analyses suggest that the contribution of FXTAS to the ataxia phenotype is less than initially proposed.

At this moment, it is important to develop corroborative studies with large samples, to answer this question.

\section{ACKNOWLEDGMENTS}

We are grateful to the people who agreed to take part in this study. Special thanks go to the patients of Hospital das Clínicas of Universidade Federal de Minas Gerais and Instituto Hermes Pardini. Research supported by grants from Instituto Hermes Pardini.

\section{REFERENCES}

Baba Y and Uitti RJ (2005). Fragile X-associated tremor/ataxia syndrome and movements disorders. Curr. Opin. Neurol. 18: 393-398.

Berry-Kravis E, Potanos K, Weinberg D, Zhou L, et al. (2005). Fragile X-associated tremor/ataxia syndrome in sisters related to X-inactivation. Ann. Neurol. 57: 144-147.

Biancalana V, Toft M, Le Ber I, Tison F, et al. (2005). FMR1 premutations associated with fragile X-associated tremor/ ataxia syndrome in multiple system atrophy. Arch. Neurol. 62: 962-966.

Brunberg JA, Jacquemont S, Hagerman RJ, Berry-Kravis EM, et al. (2002). Fragile X premutation carriers: characteristic MR imaging findings of adult male patients with progressive cerebellar and cognitive dysfunction. AJNR Am. $J$. Neuroradiol. 23: 1757-1766.

Brussino A, Gellera C, Saluto A, Mariotti C, et al. (2005). FMR1 gene premutation is a frequent genetic cause of late-onset sporadic cerebellar ataxia. Neurology 64: 145-147.

Capelli LP, Mingroni-Netto RC and Vianna-Morgante AM (2005). Structure and stability upon maternal transmission of common and intermediate FMR1 (Fragile X Mental Retardation 1) alleles in a sample of the Brazilian population. Genet. Mol. Biol. 28: 10-15.

de Vries BB, van den Ouweland AM, Mohkamsing S, Duivenvoorden HJ, et al. (1997). Screening and diagnosis for the fragile $\mathrm{X}$ syndrome among the mentally retarded: an epidemiological and psychological survey. Collaborative fragile X study group. Am. J. Hum. Genet. 61: 660-667.

de Vries BB, Mohkamsing S, van den Ouweland AM, Mol E, et al. (1999). Screening for the fragile X syndrome among the mentally retarded: a clinical study. The collaborative fragile X study group. J. Med. Genet. 36: 467-470.

Dombrowski C, Levesque S, Morel ML, Rouillard P, et al. (2002). Premutation and intermediate-size FMR1 alleles in 10572 males from the general population: loss of an AGG interruption is a late event in the generation of fragile $\mathrm{X}$ syndrome alleles. Hum. Mol. Genet. 11: 371-378.

Flannery AV, Hirst MC, Knight SJ, Ritchie RJ, et al. (1995). The fragile X syndrome. Biochim. Biophys. Acta 1271: 293-303.

Fu YH, Kuhl DP, Pizzuti A, Pieretti M, et al. (1991). Variation of the CGG repeat at the fragile X site results in genetic instability: resolution of the Sherman paradox. Cell 67: 1047-1058.

Garcia Arocena D, Louis ED, Tassone F, Gilliam TC, et al. (2004). Screen for expanded FMR1 alleles in patients with essential tremor. Mov. Disord. 19: 930-933.

Genetics and Molecular Research 7 (1): $74-84$ (2008) www.funpecrp.com.br 
Greco CM, Hagerman RJ, Tassone F, Chudley AE, et al. (2002). Neuronal intranuclear inclusions in a new cerebellar tremor/ataxia syndrome among fragile X carriers. Brain 125: 1760-1771.

Greco CM, Berman RF, Martin RM, Tassone F, et al. (2006). Neuropathology of fragile X-associated tremor/ataxia syndrome (FXTAS). Brain 129: 243-255.

Grigsby J, Leehey MA, Jacquemont S, Brunberg JA, et al. (2006). Cognitive impairment in a 65-year-old male with the fragile X-associated tremor-ataxia syndrome (FXTAS). Cogn. Behav. Neurol. 19: 165-171.

Grigsby J, Brega AG, Leehey MA, Goodrich GK, et al. (2007). Impairment of executive cognitive functioning in males with fragile X-associated tremor/ataxia syndrome. Mov. Disord. 22: 645-650.

Haddad LA, Aguiar MJ, Costa SS, Mingroni-Netto RC, et al. (1999). Fully mutated and gray-zone FRAXA alleles in Brazilian mentally retarded boys. Am. J. Med. Genet. 84: 198-201.

Hagerman RJ and Hagerman PJ (2001). Fragile X syndrome: a model of gene-brain-behaviour relationships. Rev. Neurol. 33 (Suppl 1): S51-S57.

Hagerman PJ and Hagerman RJ (2004a). Fragile X-associated tremor/ataxia syndrome (FXTAS). Ment. Retard. Dev. Disabil. Res. Rev. 10: 25-30.

Hagerman PJ and Hagerman RJ (2004b). The fragile-X premutation: a maturing perspective. Am. J. Hum. Genet. 74: 805-816.

Hagerman RJ, Leehey M, Heinrichs W, Tassone F, et al. (2001). Intention tremor, parkinsonism, and generalized brain atrophy in male carriers of fragile X. Neurology 57: 127-130.

Hagerman RJ, Leavitt BR, Farzin F, Jacquemont S, et al. (2004). Fragile-X-associated tremor/ataxia syndrome (FXTAS) in females with the FMR1 premutation. Am. J. Hum. Genet. 74: 1051-1056.

Hall DA, Berry-Kravis E, Jacquemont S, Rice CD, et al. (2005). Initial diagnoses given to persons with the fragile $\mathrm{X}$ associated tremor/ataxia syndrome (FXTAS). Neurology 65: 299-301.

Jacquemont S, Hagerman RJ, Leehey M, Grigsby J, et al. (2003). Fragile X premutation tremor/ataxia syndrome: molecular, clinical, and neuroimaging correlates. Am. J. Hum. Genet. 72: 869-878.

Jacquemont S, Hagerman RJ, Leehey MA, Hall DA, et al. (2004). Penetrance of the fragile X-associated tremor/ataxia syndrome in a premutation carrier population. JAMA 291: 460-469.

Jacquemont S, Leehey MA, Hagerman RJ, Beckett LA, et al. (2006). Size bias of fragile X premutation alleles in late-onset movement disorders. J. Med. Genet. 43: 804-809.

Jin P and Warren ST (2003). New insights into fragile X syndrome: from molecules to neurobehaviors. Trends Biochem. Sci. 28: 152-158.

Jin P, Zarnescu DC, Zhang F, Pearson CE, et al. (2003). RNA-mediated neurodegeneration caused by the fragile X premutation rCGG repeats in Drosophila. Neuron 39: 739-747.

Kamm C and Gasser T (2005). The variable phenotype of FXTAS: a common cause of "idiopathic" disorders. Neurology 65: 190-191.

Leehey MA, Munhoz RP, Lang AE, Brunberg JA, et al. (2003). The fragile X premutation presenting as essential tremor. Arch. Neurol. 60: 117-121.

MacPherson J, Waghorn A, Hammans S and Jacobs P (2003). Observation of an excess of fragile-X premutations in a population of males referred with spinocerebellar ataxia. Hum. Genet. 112: 619-620.

Mandel JL and Biancalana V (2004). Fragile X mental retardation syndrome: from pathogenesis to diagnostic issues. Growth Horm. IGF Res. 14 (Suppl A): S158-S165.

Martin RH, Lin CC, Mathies BJ and Lowry RB (1980). X-linked mental retardation with macro-orchidism and marker-X chromosomes. Am. J. Med. Genet. 7: 433-441.

Oostra BA and Willemsen R (2003). A fragile balance: FMR1 expression levels. Hum. Mol. Genet. 12 (Spec No. 2): R249-R257.

Richards BW, Sylvester PE and Brooker C (1981). Fragile X-linked mental retardation: the Martin-Bell syndrome. $J$. Ment. Defic. Res. 25: 253-256.

Rogers C, Partington MW and Turner GM (2003). Tremor, ataxia and dementia in older men may indicate a carrier of the fragile X syndrome. Clin. Genet. 64: 54-56.

Rousseau F, Rouillard P, Morel ML, Khandjian EW, et al. (1995). Prevalence of carriers of premutation-size alleles of the FMRI gene - and implications for the population genetics of the fragile $\mathrm{X}$ syndrome. Am. J. Hum. Genet. 57: 1006-1018.

Sambrook J and Russell DW (2001). Rapid isolation of mammalian DNA. In: Molecular cloning: a laboratory manual. 3rd edn. Cold Spring Harbor Laboratory, New York.

Seixas AI, Maurer MH, Lin M, Callahan C, et al. (2005). FXTAS, SCA10, and SCA17 in American patients with movement disorders. Am. J. Med. Genet. A 136: 87-89.

Tan EK, Zhao Y, Puong KY, Law HY, et al. (2004). Fragile X premutation alleles in SCA, ET, and parkinsonism in an Asian cohort. Neurology 63: 362-363.

Genetics and Molecular Research 7 (1): 74-84 (2008) www.funpecrp.com.br 
Toft M, Aasly J, Bisceglio G, Adler CH, et al. (2005). Parkinsonism, FXTAS, and FMR1 premutations. Mov. Disord. 20: 230-233.

Turner G, Webb T, Wake S and Robinson H (1996). Prevalence of fragile X syndrome. Am. J. Med. Genet. 64: 196-197. Van Dam D, Errijgers V, Kooy RF, Willemsen R, et al. (2005). Cognitive decline, neuromotor and behavioural disturbances in a mouse model for fragile-X-associated tremor/ataxia syndrome (FXTAS). Behav. Brain Res. 162: 233-239.

Van Esch H (2006). The Fragile X premutation: new insights and clinical consequences. Eur. J. Med. Genet. 49: 1-8.

Van Esch H, Dom R, Bex D, Salden I, et al. (2004). Screening for FMR-1 premutations in 122 older Flemish males presenting with ataxia. Eur. J. Hum. Genet. 13: 121-123.

Willemsen R, Hoogeveen-Westerveld M, Reis S, Holstege J, et al. (2003). The FMR1 CGG repeat mouse displays ubiquitin-positive intranuclear neuronal inclusions; implications for the cerebellar tremor/ataxia syndrome. Hum. Mol. Genet. 12: 949-959.

Willemsen R, Mientjes E and Oostra BA (2005). FXTAS: a progressive neurologic syndrome associated with fragile X premutation. Curr. Neurol. Neurosci. Rep. 5: 405-410.

Zühlke C, Budnik A, Gehlken U, Dalski A, et al. (2004). FMR1 premutation as a rare cause of late onset ataxia-evidence for FXTAS in female carriers. J. Neurol. 251: 1418-1419.

Zumrova A, Mazanec R, Vyhnalek M, Krepelova A, et al. (2005). Concomitancy of mutation in FRDA gene and FMR1 premutation in 58-year-old woman. Neuro Endocrinol. Lett. 26: 71-74.

Genetics and Molecular Research 7 (1): $74-84$ (2008) www.funpecrp.com.br 